\title{
Inference of Ground Surface Temperature History from Subsurface Temperature Data: Interpreting Ensembles of Borehole Logs
}

\author{
Henry N. Pollack, ${ }^{1}$ Po Yu Shen ${ }^{2}$ and Shaopeng Huang ${ }^{1}$
}

\begin{abstract}
Ground surface temperature histories (GSTHs) inferred from borehole temperaturedepth $(T-z)$ data are often degraded, to a various extent, by random or systematic noise in the $T-z$ data and in the measurements of thermophysical properties of the earth. To minimize the effects of noise, and hence improve the fidelity of the inferred GSTH, a plausible approach is to perform a simultaneous inversion of the $T-z \operatorname{logs}$ in a region, or alternatively, to invert the individual $T-z \operatorname{logs}$ and then average the resulting GSTHs. Averaging and simultaneous inversion are conceptually different: whereas an averaging can always be peformed, a simultaneous inversion is predicated on the assumption of a common transient component of the GSTH in all the $T-z$ logs. In this work we examine and compare the two approaches, using a time domain inverse formulation based on the method of least squares. We consider a set of scenarios: (a) multiple $T-z$ logs from a single borehole, (b) multiple boreholes from a single site, (c) multiple boreholes in similar climatological settings, and (d) multiple boreholes in different climatological settings. We show that for (a), (b) and (c), averaging and simultaneous inversion yield nearly identical results. For boreholes in different settings, the assumption of a common transient GSTH may be invalid and averaging and simultaneous inversion give divergent results.
\end{abstract}

Key words: Borehole temperature, climate change, inversion.

\section{Introduction}

A principal focus of recent geothermal investigations has been the reconstruction of temperature changes that have occurred at the earth's surface by analyzing the perturbations those changes have imposed on the subsurface temperature field (e.g., Beltrami and MAReschal, 1991; MACAyeal et al., 1991; SHEN and BECK, 1991, 1992; MARESCHAL and Beltrami, 1992; WANG, 1992; WANG et al., 1992; WANG and LeWIS, 1992; BelTRAMI et al., 1992; HARRIS and CHAPMAN, 1995; SHEN et al., 1995, 1996; Clauser and MARESChal, 1995; BEltrami and MARESCHAL, 1995; HUANG et al., 1996). This area of research has recently burgeoned because the information contained in subsurface temperatures can, under optimal circumstances, extend our knowledge of the temporal and spatial

\footnotetext{
${ }^{1}$ Department of Geological Sciences, University of Michigan, Ann Arbor, Michigan 48109-1063, U.S.A.

${ }^{2}$ Department of Earth Sciences, University of Western Ontario, London, N6A 5B7, Canada.
} 
variability of surface climate back in time several centuries prior to the more recent instrumental record provided by meteorological stations. However, as in all geophysical endeavors, the extraction of a signal from an ensemble of observations is impeded by the presence of noise. As noted by SHEN et al. (1995), the noise in this system derives not only from errors in the measurements of temperatures, depths, and thermophysical properties of the earth's materials, but also from the "representational" errors, i.e., departures of the mathematical representation of the system from conditions such as subsurface heterogeneity and advective heat transfer that may exist in the real world. SHEN et al. (1995) pointed out that all existing approaches to reconstructing a surface temperature history from subsurface temperatures are conceptualized in terms of one-dimensional heat conduction. Their paper then focused on the limitations that three-dimensional heterogeneity of subsurface thermophysical properties imposed on the recovery of a surface temperature history, and on identifying optimal inversion constraints that would effectively suppress noise without unduly suppressing the signal as well.

Here we explore another approach to the extraction of a climate signal from subsurface temperatures. This approach is based on the philosophy that in an analysis of a system comprising both signal and noise, the signal can be enhanced and the noise suppressed by analyzing multiple observations of the system taken together as an ensemble. The concept is analogous to that of signal enhancement via record stacking in the analysis of seismic reflection data. Cast into a field context, one can envision an array of boreholes at a mineral exploration site. The boreholes may be sited in clearings or vegetation, on hills or in valleys, on sunny or shaded slopes and drilled into different rock types and subsurface structures. Therefore temperature-depth $(T-z)$ profiles from different boreholes may contain different location-specific perturbations. However, if the atmosphere in this region were undergoing a slow secular change in temperature because of a long-term change in climate, all the boreholes would perhaps experience this common transient perturbation to the surface temperature. A combined analysis of all the borehole temperature profiles may have a better chance of identifying the common transient than would an analysis of observations from any single borehole. The same principle would apply to several logs from a single borehole taken at different times.

\section{Theoretical Framework}

Clauser and MAREschal (1995) presented a simultaneous inversion of data from central Europe, using the method of singular value decomposition (SVD), and Beltrami and MARESCHAL (1995) briefly explored, in the SVD context, some aspects of averaging versus simultaneous inversion. Here we apply a simultaneous inverse formulation which is an extension of the functional space inverse (FSI) 
method proposed by SHEN and BECK (1991) and implemented and applied by SHEN and BeCK (1992) and SHEN et al. (1995). The extension is based on the assumption that the participating boreholes have experienced the same transient variations in ground surface temperature history (GSTH). The individual boreholes may have independent or common thermophysical properties structures as well as independent or common steady-state reference thermal regimes. Given a distribution of thermophysical properties in the subsurface, the reference thermal regime is controlled by two parameters: the ground surface temperature prior to the onset of the surface transient, and the background heat flow density. For computational expediency we restrict the model to be estimated to the following components: the common transient variation in the GSTH at all sites, and the reference steady-state surface temperature, the background heat flow density, and the thermal conductivity structure for each individual borehole. Other parameters such as the specific heat capacity and the heat production rate, which are known to play minor roles in the inverse problem (SHEN and BECK, 1991, 1992) are treated as known quantities. The formulation is a straightforward application of the nonlinear least squares inverse theory of TARANTOLA and VAletTe (1982a,b) and TARANTOla (1988).

The fundamental difference between simultaneous inversion and simple averaging of individual inversions is that the former seeks a common model of ground surface temperature variation which is consistent with all the $T-z \operatorname{logs}$ within a given misfit tolerance, whereas the latter gives an average which does not directly incorporate or systematically accommodate all of the data in the individual logs. Here data refer to both the $T-z$ measurements and the thermophysical properties measurements for each of the participating boreholes. The simultaneous inversion can also take into account the data distributions and data uncertainties. For example, dense or high quality data from a certain section of one borehole can be assigned more weight in the estimation of GSTH relative to sparse or poor data from a corresponding section of another borehole. The effects of such selective weighting cannot be duplicated easily in an averaging.

\section{Synthetic Example}

Before analyzing real field data, we start with a synthetic experiment to illustrate the various considerations involved in simultaneous inversion and/or averaging. We generate nine sets of "climate-perturbed" $T-z$ data, simulating data from nine boreholes, in a three-dimensional random medium (see SHEN et al., 1995), using a synthetic ground surface temperature history constructed from an annual surface air temperature time series derived from tree ring data analyses (JACOBY and D'ARRIGO, 1989; JACOBY, pers. comm.). The nine data sets are then inverted to study the extent to which the perturbing ground surface temperature history may be recovered. The results from individual inversion and from averaging/simultaneous 

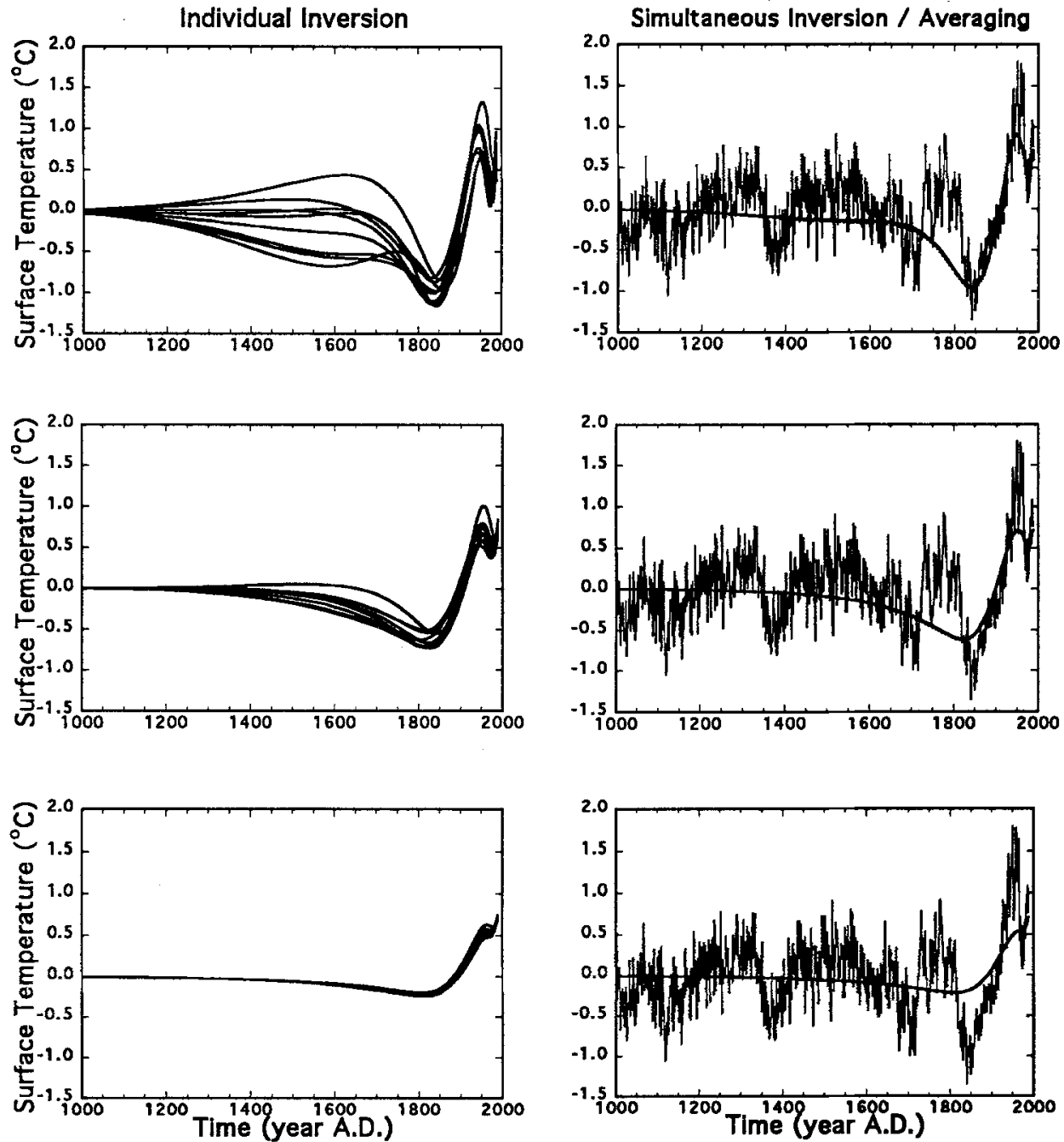

Figure 1

Estimated ground surface temperature histories from the nine synthetic data sets with tight (upper panels), moderate (middle panels) and loose (lower panels) constraints on borehole data. Left panels display results from individual inversions; right panels show results of simultaneous inversion and averaging. Shown in the right panels is also the high frequency signal derived from tree ring data (JACOBY and D'ARRIGO, 1989).

inversion are shown in the left and the right panels of Figure 1, respectively. Individual inversions of the nine data sets (left panels) do not give identical results because the three-dimensional random earth has been misrepresented as a uniform medium during inversion, consequently the nine data sets are in effect contaminated with different sequences of representational noise. To mute the artifacts of the representational noise, we consider three different levels of constraints on the $T-z$ 
data and thermophysical properties. From top to bottom in Figure 1, the borehole temperature and thermal conductivity data have been tightly, moderately, and loosely constrained, respectively, during inversion. A tight constraint means that relatively great weight is given to the data in the inversion, whereas a loose constraint means that relatively little weight is given. A comparison of the corresponding left and right panels reveals the benefit of having multiple logs: for an individual inversion, the borehole data must be moderately to loosely constrained in order to adequately suppress the artifacts of noise, leading to an oversmoothing of the estimated GSTH, and muting of the amplitude of variation. The availability of multiple logs allows the use of tighter constraints on data, thus leading to a less muted reconstruction of the true GSTH. In this synthetic experiment, we use four different approaches to averaging and simultaneous inversions: (a) the nine sets of $T-z$ data are averaged and the average $T-z \log$ is then inverted; (b) the nine logs are individually inverted and the resulting GSTHs are averaged; (c) the nine logs are simultaneously inverted, assuming that each site has independent thermophysical properties structure and independent reference $T$-z profile; and (d) the nine logs are simultaneously inverted, assuming a common thermophysical properties structure and reference $T-z$ profile (i.e., the nine logs are assumed to be taken from the same borehole). Shown in Figure 1 are only results from (b) and (c); within the resolution of the graph all four approaches to averaging/simultaneous inversion yield nearly identical results. Although there is a risk of misinterpreting the GSTH by inversion of a single log with tight constraints on the borehole data (upper left panel of Figure 1), an interpretation of the ensemble of logs by either simultaneous inversion or averaging, with the same tight constraints, will yield a better estimate of the true GSTH than will the same procedures applied under looser constraints on data. In other words, simultaneous inversion/averaging can share the burden of noise suppression and amplitude resolution of the GSTH with the other constraints on data in the inversion. The lack of resolution of the inferred GSTHs seen in the earlier part of the representation time interval reflects the progressive loss of information with time in a diffusive system, and would be characteristic of any reconstructions, by whatever method, at this level of noise. These excellent results emerge because in this idealized synthetic example, the nine logs are taken at identical times, the noise has a Gaussian distribution and the spatial distributions of the $T-z$ data and of the thermophysical properties measurements are identical for the nine sites. This will not be the case for real data, however, where none of the idealizations are likely to be met, and the different sites will not likely have experienced identical GSTHs. Nevertheless, the idealized example offers sufficient promise to encourage a similar analysis of ensembles of real data. Below, we apply the simultaneous inversion/averaging methodology in four scenarios drawn from real data sets from central and eastern Canada: (a) multiple $T-z$ logs from a single borehole, (b) multiple boreholes from a single site, (c) multiple boreholes in similar climatological settings, and (d) multiple boreholes in different climatological set- 


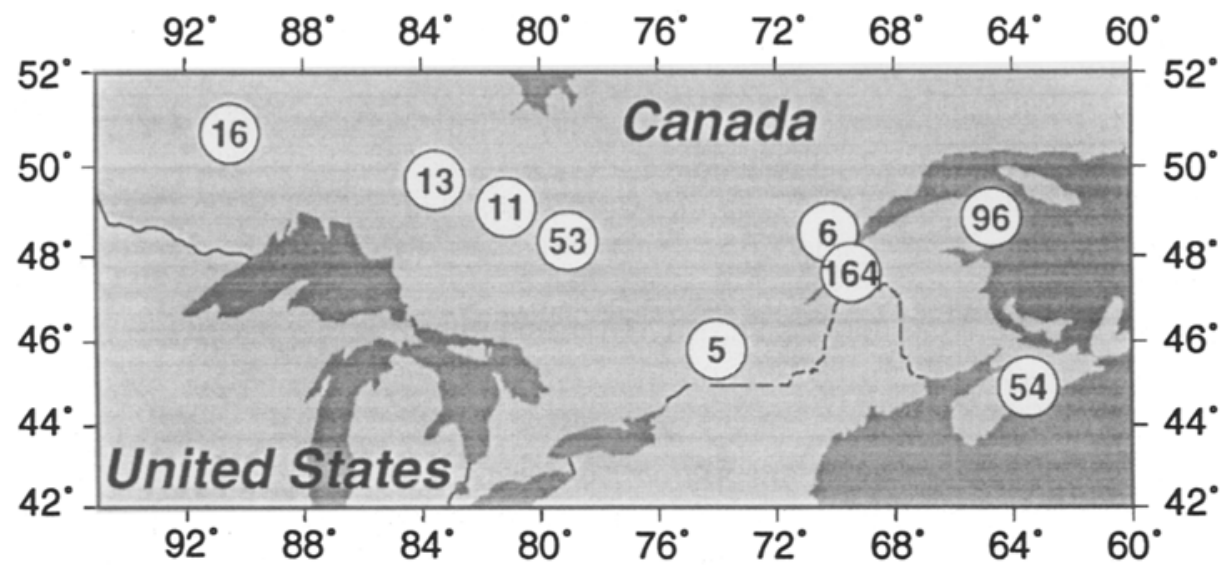

Figure 2

Map showing location of the selected borehole sites in central and eastern Canada.
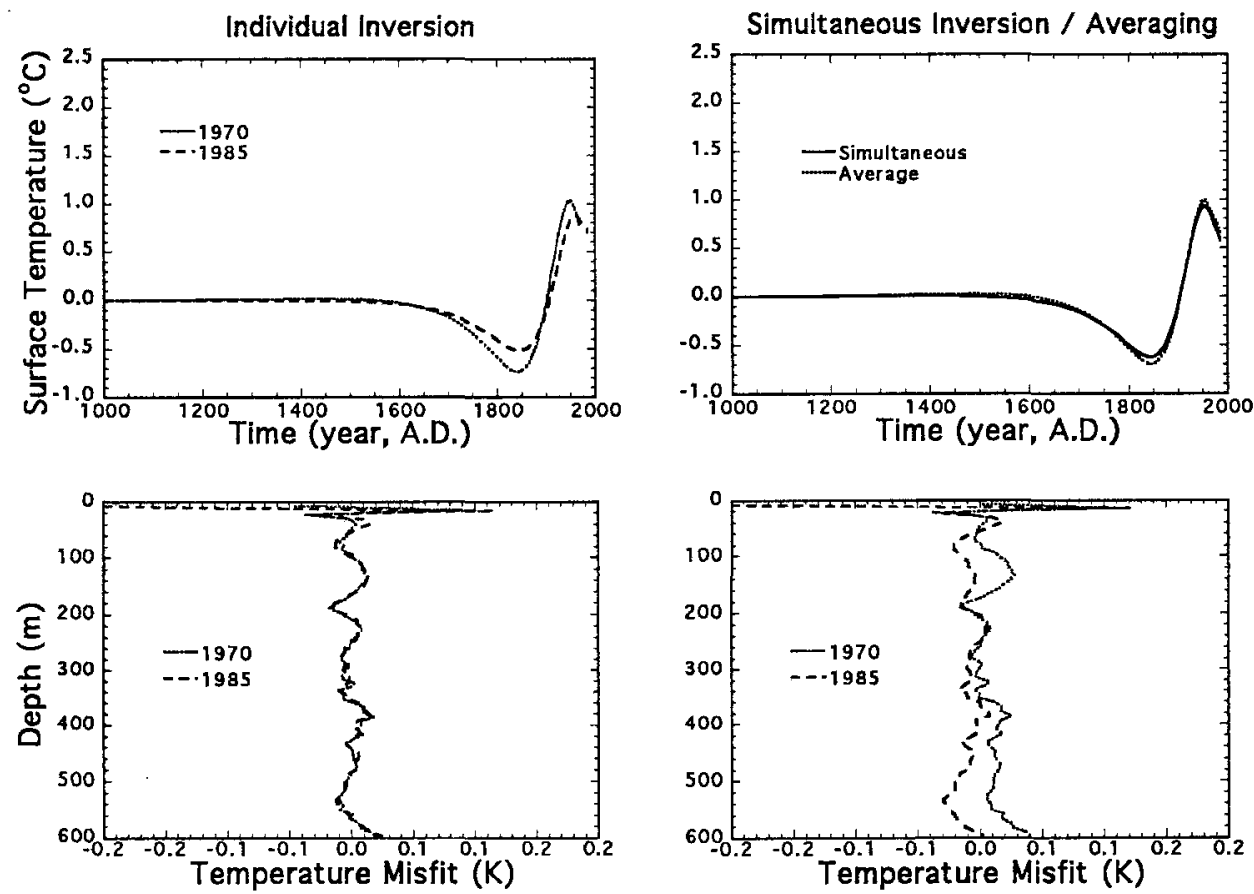

Figure 3

Estimated ground surface temperature histories (upper panels) and misfits in temperature-depth data (lower panels) for the two temperature profiles measured in the Minchin Lake borehole (Site 16 in Figure 2) in 1970 and 1985, respectively. 
tings. In these four scenarios, the assumption of a common transient GSTH ranges successively from strictly valid to questionable.

\section{Multiple Logs from a Single Borehole}

The simplest scenario of a simultaneous inversion of multiple logs is when several $T-z \operatorname{logs}$ have been made in the same borehole at various times in the past. Under such a circumstance, the reference thermal regime, the distribution of the thermophysical properties and other terrain characteristics all remain constant. It is therefore reasonable to assume that all the participating logs are related to a common GSTH and an identical thermophysical model. Several boreholes in central and eastern Canada have been logged twice in the last 30 years, allowing for simultaneous inversion of this scenario. The two $T-z \operatorname{logs}$ taken from the borehole at Minchin Lake (site 16 in Figure 2) in 1970 and 1985 are analyzed as an example of this kind of inversion. The earlier log was obtained by CERMAK (1971) and the later $\log$ by NIELSEN and BECK (1989). The inferred GSTHs from these two Minchin Lake logs are shown in Figure 3. We see that individual inversions of the two logs yield similar but not identical results, indicating the probable presence of some different perturbations that are not attributable to changes in the ground surface temperature. However, these non-climatic perturbations are small, therefore the result from a simultaneous inversion falls between those from the individual inversions (left panel)* and is nearly identical to the result of averaging the individual inversions (right panel). The lower panels of Figure 3 show the data misfits, i.e., the difference between the measured and the predicted $T-z$ profiles. The simultaneous inversion, not surprisingly, displays a greater misfit. One would expect a better data fit in individual inversions than in a simultaneous inversion, because in inversion of a single $\log$, both the thermophysical model and the transient GST model are more readily adjusted, in terms of deviation of the subsurface temperature from the reference steady-state, whereas in a simultaneous inversion of multiple logs, a single set of model parameters must incorporate simultaneously the deviations in all the participating $T-z$ logs.

\section{Multiple Boreholes from a Single Site}

There are cases in which the data sets derive from a group of boreholes in a close proximity such that they may be considered to be from a single site. We can

\footnotetext{
* An earlier analysis by SHEN and BECK (1992) had shown that the result of a simultaneous inversion tended to merge with that of the individual inversion of the first (earlier) log. It is now known that this bias stems from the use of different parameterizations in the simultaneous and individual inversions, a practice which favors the contribution from the first log and thus renders inappropriate a strict comparison of the results. Our present analysis overcomes this problem.
} 

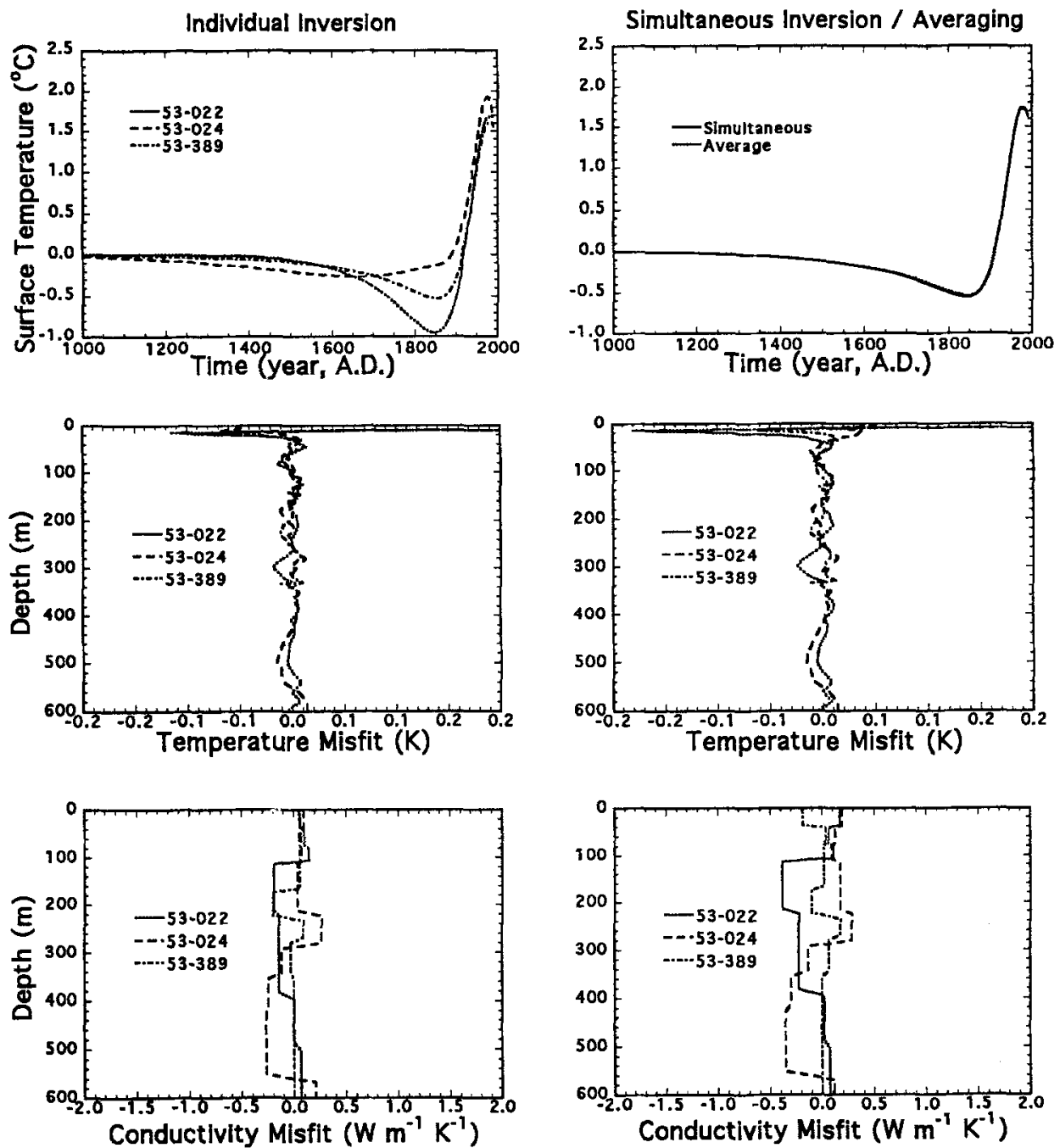

Figure 4

Estimated ground surface temperature histories (upper panels), misfits in temperature-depth data (middle panels), and misfits in thermal conductivity data (lower panels) for boreholes 53-022, 53-024 and 53-389 at Lac Dufault (Site 53 in Figure 2).

expect these borehole locations to have approximately the same heat flow density and have experienced approximately the same GSTH so that an averaging or simultaneous inversion should help to recover the true GSTH by reducing the effects of location-specific terrain and subsurface structural perturbations. The boreholes at Lac Dufault (Site 53 in Figure 2), near Noranda, Quebec provide a good example for such a study. Numerous boreholes distributed in a $5 \mathrm{~km}^{2}$ area were logged in 1968 (LEWIS and BECK, 1977) and twelve were relogged in 1990 
(LEWIS and WANG, 1992). Three of the boreholes, 53-022, 53-024 and 53-389 have been analyzed previously by WANG et al. (1992) and SHEN et al. (1995). Here we compare the results of simultaneous inversion and averaging, using only the 1990 logs of these three boreholes. The estimated GSTHs are shown in the upper panels of Figure 4. The individual inversions show consistency except for an amplitude variation in the temperature low around $1850 \mathrm{AD}$. This translates into an almost perfect match between simultaneous inversion and averaging. It is instructive to examine the misfits in $T-z$ profiles (middle panels of Figure 4) and in thermal conductivity-depth $(K-z)$ profiles (lower panels of Figure 4). In both figures, the left panel shows the misfit in the individual inversions whereas the right panel shows the misfit in the simultaneous inversion. The fact that the three data sets are consistent with a single GSTH is reflected in the similarity of the right and left panels of Figure 4 . We shall see in the next example, when we seek to estimate a common GSTH for a larger region, the $T-z$ and $K-z$ misfits in a simultaneous inversion increase correspondingly. Ultimately, as we increase the region of coverage, the misfits may become unreasonably large, indicating the breakdown of the hypothesis of a common GSTH.

\section{Multiple Sites in a Similar Climatological Setting}

We now turn to an example of simultaneous inversion of observations from several sites separated by a few hundred kilometers. In this scenario, the sites are close enough in a common climatological environment to anticipate that there may be a common GSTH. However, each site must be considered as different from all other sites in terms of reference thermal regimes and all surface characteristics. We consider four sites in central Canada with a minimum separation of $80 \mathrm{~km}$ and a maximum separation of $1000 \mathrm{~km}$. Two of the sites, Minchin Lake and Lac Dufault, have already been analyzed and discussed. The two additional sites are Hearst (Site 13 in Figure 2) and Cochrane (Site 11 in Figure 2), each logged in 1969 (CERMAK, 1971) and again in 1985 (NIELSEN and BECK, 1989). Hearst and Cochrane are roughly similar in that they both exhibit a large recent temperature rise. Minchin Lake and Lac Dufault are also similar, but with a more modest recent rise. However, the patterns of surface temperature changes clearly suggest a common perturbation. We perform the averaging and simultaneous inversion, but as the three Lac Dufault holes represent a single site, we assign to each of them only $1 / 3$ of the weight of a single site. The estimated GSTHs, $T-z$ and $K-z$ misfits are shown in Figure 5, respectively. These plots demonstrate that it is reasonable to consider the four sites to have a common GSTH, although the $K-z$ misfits are at the limit of observational errors. 

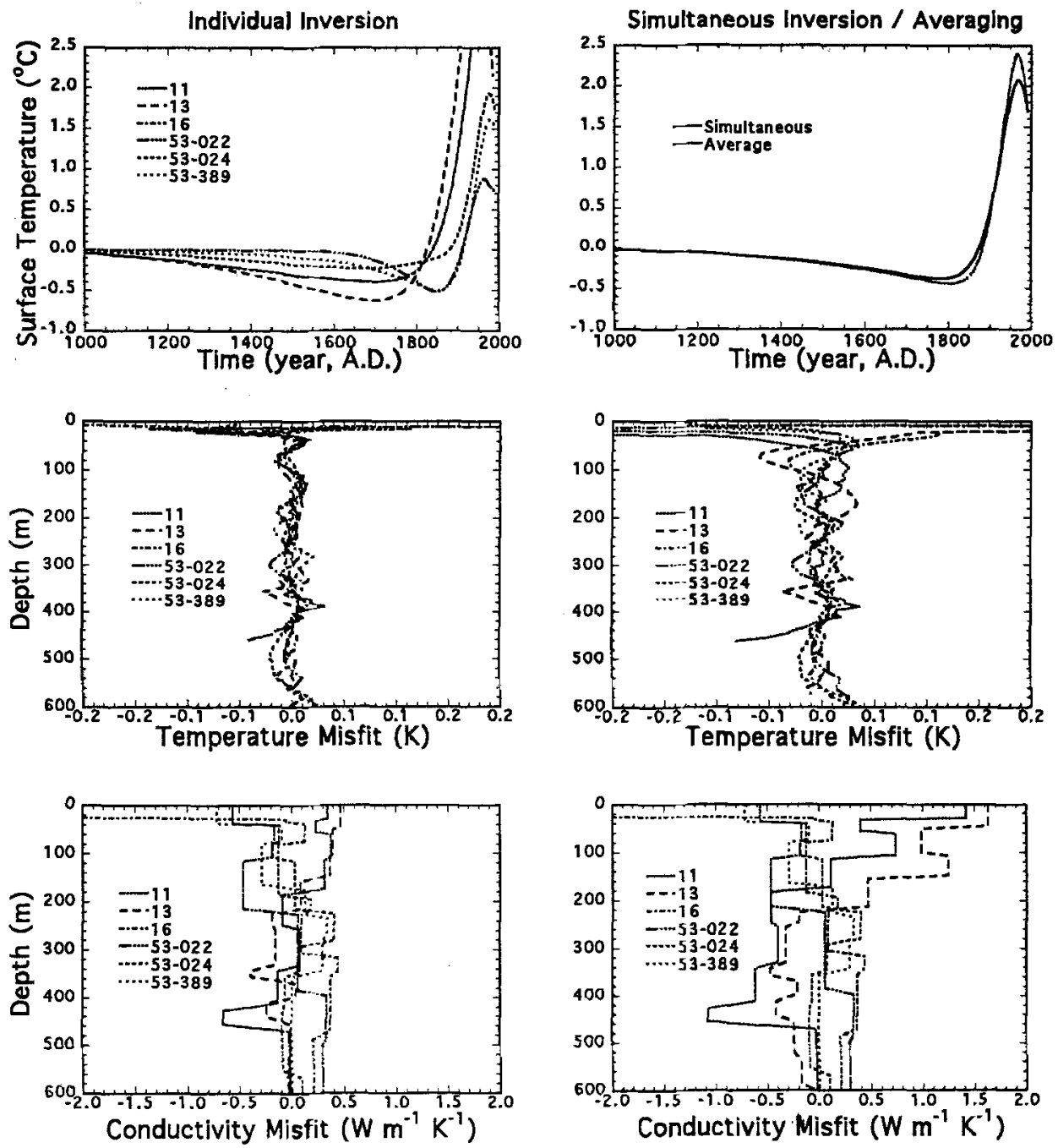

Figure 5

Estimated ground surface temperature histories (upper panels), misfits in temperature-depth data (middle panels), and misfits in thermal conductivity data (lower panels) for Cochrane (Site 11), Hearst

(Site 13), Minchin Lake (Site 16), and three boreholes at Lac Dufault (Site 53).

\section{Multiple Sites in Different Climatological Settings}

We now consider the simultaneous inversion of data sets from sites in an extended region where the assumption of a common transient may be questionable. A good example comprises five holes in eastern Canada: St. Jerome, Roberval, Oldham, Sunny Bank, and Parke (Sites 5, 6, 54, 96, and 164 in Figure 2). These boreholes are spread over an area of some $300,000 \mathrm{~km}^{2}$, with minimum and 

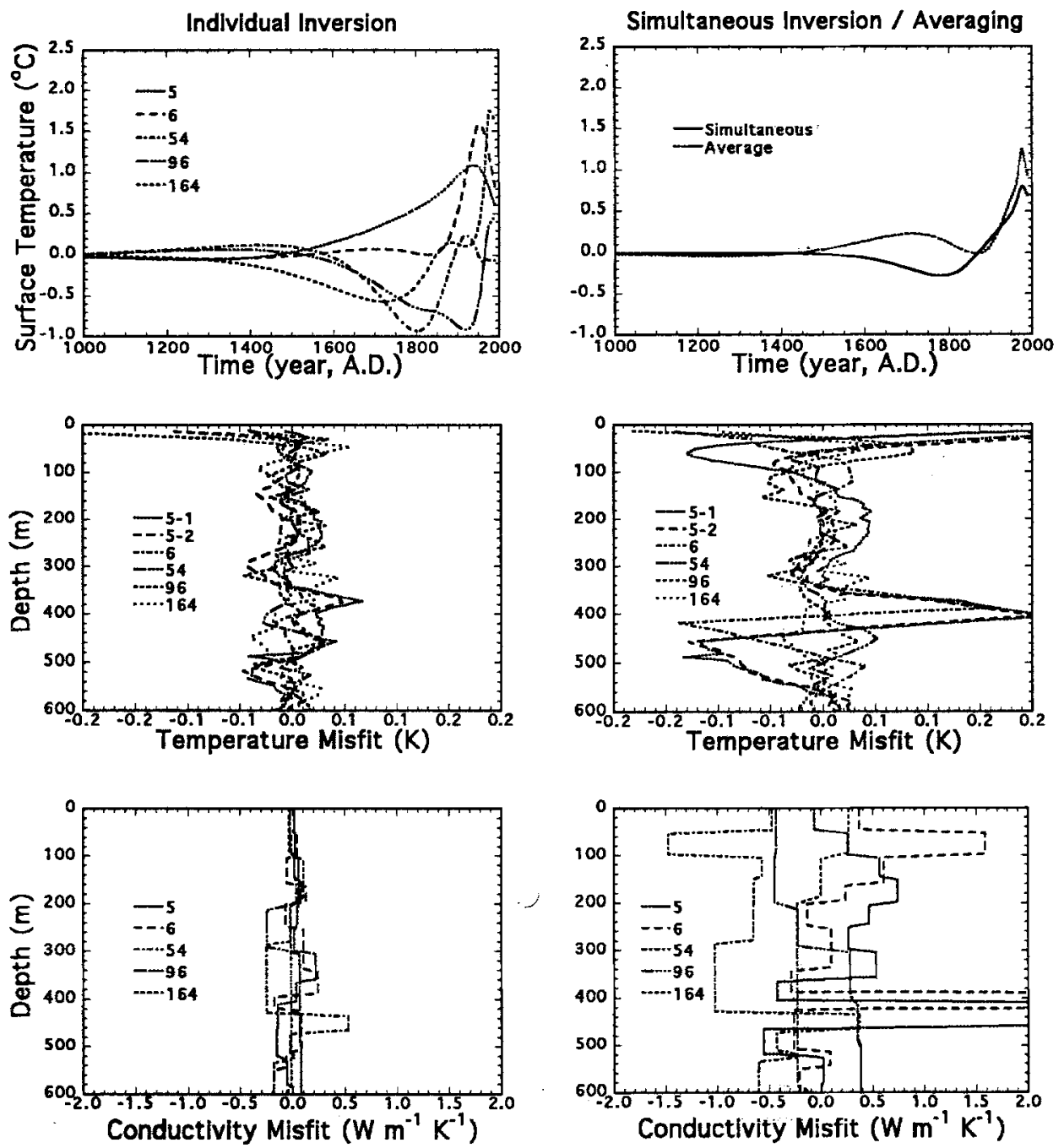

Figure 6

Estimated ground surface temperature histories (upper panels), misfits in temperature-depth data (middle panels), and misfits in thermal conductivity data (lower panels) for boreholes from five sites

(Site 5, 6, 54, 96, and 164 in Figure 2) in eastern Canada.

maximum separations of 200 and $800 \mathrm{~km}$, respectively. However, the sites range in climatological setting from maritime to continental interior. The inversion results for these holes, given by SHEN et al. (1995), HUANG et al. (1996) and also earlier by WANG et al. (1992), have also shown a range of scatter sufficient to render questionable the hypothesis of a common GSTH. This is borne out by the results shown in Figure 6 for the estimated GSTHs, the $T-z$ and $K-z$ misfits. In order to accommodate a common transient GSTH, the subsurface temperatures (middle 
right panel, Figure 6) and the thermal conductivities (lower right panel, Figure 6) for some of the boreholes must take unlikely adjusted values, as indicated by the misfits. For this group of boreholes, a simultaneous inversion has little credibility. Averaging is permissible but it will be accompanied by a large standard deviation, thus also indicating a lack of significance.

\section{Discussion and Conclusions}

The motivation for simultaneous inversion of multiple borehole logs is to interrogate them for a common transient GSTH. From a scenario of multiple $T-z$ logs in a single borehole to that of multiple logs from widely separated multiple boreholes, the likelihood of a common transient GSTH, a common reference thermal regime, and similar location-specific perturbations ranges from very high to very low. In seeking a common transient GSTH that simultaneously accommodates all $T-z$ logs and thermal conductivity measurements from the different boreholes, with possibly different thermal regimes, terrain effects, and true GSTHs, one typically observes significantly larger data misfits for the individual boreholes. The larger data misfits in a simultaneous inversion of multiple logs account for not only various non-climatic perturbations, but also local terrain-related microclimate effects.

An averaging of the individual inversions of data from different boreholes can always be accomplished, but a simultaneous inversion can provide an indication of when it should not be done. The indication arises from the magnitude of the data misfits in both temperature and thermal conductivity that must be accommodated to achieve a simultaneous inversion. When these misfits become unrealistically large, a common transient GSTH may not exist.

The efficacy of a simultaneous inversion in suppressing the effects of observational and representational noise is clear, and in principle the more logs available the better, provided all are of high quality. Moreover, simultaneous inversion relieves the inversion constraints of carrying the entire burden of noise suppression, thus allowing those constraints to be tightened to extract incremental information concerning the GSTH that is lost when looser constraints on data are used. The advantages of a simultaneous inversion obviously include the representation of a regional GSTH consistent with the site histories at individual borehole locations. This methodology also has clear application to estimating the correlation scale length of climate change from geothermal data, for comparison with that determined from meteorological data (HANSEN and LEBEDEFF, 1987; ChAPMAN et al., 1992).

\section{Acknowledgements}

This research has been supported by the Climate Dynamics Program of the U.S. National Science Foundation under Grant ATM 9320004. We thank J. A. Majorowicz and R. N. Harris for their thoughtful comments on the manuscript. 


\section{REFERENCES}

Beltrami, H., Jessop, A. M., and Mareschal, J.-C. (1992), Ground Temperature Histories in Eastern and Central Canada from Geothermal Measurements: Evidence of Climate Change, Palaeogeogr. Palaeoclimatol. Palaeoecol. (Global Planet. Change Sect.) 98, 167-183.

Beltrami, H., and Mareschal, J.-C. (1991), Recent Temperature Changes in Eastern Canada Inferred from Geothermal Measurements, Geophys. Res. Lett. 18, 605-608.

Beltrami, H., and MAReschal, J.-C. (1995), Resolution of Ground Temperature Histories Inverted from Borehole Temperature Data, Palaeogeogr. Palaeoclimatol. Palaeoecol. (Global Planet. Change Sect.) $11,57-70$.

Cermak, V. (1971), Underground Temperature and Inferred Climatic Temperature of the Past Millennium, Palaeogeogr. Palaeoclimatol. Palaeoecol. 10, 1-19.

Chapman, D. S., Chisholm, T. J., and Harris, R. N. (1992), Combining Borehole Temperature and Meteorological Data to Constrain Past Climate Change, Palaeogeogr. Palaeoclimatol. Palaeoecol. (Global Planet. Change Sect.) 98, 269-281.

Clauser, C., and Mareschal, J.-C. (1995), Ground Temperature History in Central Europe from Borehole Temperature Data, Geophys. J. Int. 121, 805-817.

Hansen, J., and LebedefF, S. (1987), Global Trends of Measured Surface Air Temperature, J. Geophys. Res. 92, 13345-13372.

HARris, R. N., and ChAPMAN, D. S. (1995), Climate Change on the Colorado Plateau of Eastern Utah Inferred from Borehole Temperatures, J. Geophys. Res. 100, 6367-6381.

Huang, S., Shen, P. Y., and Pollack, H. N. (1996), Deriving Century-long Trends of Surface Temperature Change from Borehole Temperatures with a Few-parameter Estimation Technique, Geophys. Res. Lett. 23, 257-260.

JACOBY, G. C., and D'ARrigo, R. (1989), Reconstructed Northern Hemisphere Annual Temperature since 1671 Based on High-latitude Tree-ring Data from North America, Clim. Change 14, 39-59.

LEwIS, T. J., and BECK, A. E. (1977), Analysis of Heat-flow Data-Detailed Observations in Many Holes in a Small Area, Tectonophysics 41, 41-59.

LEwIS, T. J., and WANG, K. (1982), Influence of Terrain on Bedrock Temperatures, Palaeogeogr. Palaeoclimatol. Palaeoecol. (Global Planet. Change Sect.) 98, 81-100.

MacAyeal, D. R., Firestone, J., and Waddington, E. (1991), Paleothermometry by Control Methods, J. Glaciol. 37, 326-338.

MARESCHAL, J.-C., and BeLTRAMI, H. (1992), Evidence for Recent Warming from Perturbed Geothermal Gradients: Examples from Eastern Canada, Clim. Dynam. 6, 135-143.

Nielsen, S. B., and BECK, A. E. (1989), Heat Flow Density Values and Paleoclimate Determined from Stochastic Inversion of four Temperature-depth Profiles from the Superior Province of the Canadian Shield, Tectonophysics 164, 345-359.

SHEN, P. Y., and BECK, A. E. (1991), Least Squares Inversion of Borehole Temperature Measurements in Functional Space, J. Geophys. Res. 96, 19,965-19,979.

Shen, P. Y., and Beck, A. E. (1992), Paleoclimate Change and Heat Flow Density Inferred from Temperature Data in the Superior Province of the Canadian Shield, Palaeogeogr. Palaeoclimatol. Palaeoecol. (Global Planet. Change Sect.) 98, 143-165.

Shen, P. Y., Pollack, H. N., Huang S., and WANG, K. (1995), Effects of Subsurface Heterogeneity on the Inference of Climate Change from Borehole Temperature Data: Model Studies and Field Examples from Canada, J. Geophys. Res. 100, 6383-6396.

Shen, P. Y., Pollack, H. N., and HUANG, S. (1996), Inference of Ground Surface Temperature History From Borehole Temperature Data: A Comparison of Two Inverse Methods, Palaeogeogr. Palaeodimatol. Palaeoecol. (Global Planet. Change Sect.), in press.

Tarantola, A. (1988), Theoretical Background for the Inversion of Seismic Waveforms, Including Elasticity and Attenuation, Pure and Appl. Geophys. 128, 365-399.

Tarantola, A., and VAlette, B. (1982a), Generalized Nonlinear Inverse Problems Solved Using the Least Squares Criterion, Rev. Geophys. 20, 219-232.

Tarantola, A., and ValetTe, B. (1982b), Inverse Problems $=$ Quest for Information, J. Geophys. 50, $159-170$. 
WANG, K. (1992), Estimation of Ground Surface Temperatures from Borehole Temperature Data, J. Geophys. Res. 97, 2095-2106.

WANG, K., and LEWIS, T. J. (1992), Geothermal Evidence from Canada for a Cold Period before Recent Climatic Warming, Science 256, 1003-1005.

Wang, K., LewIs, T. I., and Jessop, A. M. (1992), Climatic Changes in Central and Eastern Canada Inferred from Deep Borehole Temperature Data, Palaeogeogr. Palaeoclimatol. Palaeoecol. (Global Planet. Change Sect.) $98,129-141$.

(Received December 13, 1995, accepted February 20, 1996) 